\title{
Detection Myocardial Bridging Using Non-Invasive Technique
}

\author{
Junbo Ge and Jianying Ma \\ Shanghai Institute of Cardiovascular Diseases \\ Zhongshan Hospital, Fudan University
}

China

\section{Introduction}

Myocardial bridging(MB) is considered as a congenital condition. Usually, coronary artery runs through epicardially. Myocardial bridging occurs when a segment of a coronary artery or its major branch travels intramurally through the myocardium. The myocardium overlying the intramural segment of epicardial coronary artery is called a myocardial bridging, and the artery coursing within the myocardium is called a "tunneled artery". It may dip into the myocardium for varying lengths. The mid portion of left anterior coronary artery has been reported as the most frequent site of myocardial bridges. This phenomenon was first described by Grainicianu in the early 1920s. In 1960, Portmann and Iwig first reported the radiological appearance of transient occlusion in a segment of the left anterior descending coronary artery during systole. A large discrepancy exists between pathological series, in which the incidence has varied from $15 \%$ to $85 \%$, and angiographic series, in which it is reported as being between $0.51 \%$ and $2.5 \%$.

The clinical significance of $\mathrm{MB}$ is controversial. Myocardial bridging has been shown linking to clinical complications that include ischemia, acute coronary syndrome, coronary spasm, arrhythmia, and sudden death, although in the vast majority of cases, myocardial bridging remains clinically silent.

Coronary angiography remains the current gold standard for diagnosing MB. Lower prevalence of myocardial bridging on coronary angiography may partly due to thin bridging. In addition, coronary angiography is an invasive technique with complications and risks. Until now, intravascular ultrasound (IVUS) is the most accurate method to diagnose MB. Intracoronary Doppler ultrasound (ICD) has also been used in the diagnosis of bridging. However, they are all invasive and expensive and not routinely used in clinical settings. Therefore, the need for a non-invasive technique for detection of bridging has emerged. While multi-detector computed tomography (MDCT) angiography is faster and more adequate, it has the ability to assess the course and the anatomic relationships of the coronary arteries. With the advent of high-resolution magnetic resonance imaging and shorter scan time, it will have a bright future for the reason of no contrast and radiation.

In this paper, we will discuss the non-invasive method to detect myocardial bridging in comparison to invasive technique. 


\section{Prevalence}

The prevalence varies substantially among different studies. It was higher at autopsy studies than conventional coronary angiographical studies. The incidence of myocardial bridging among postmortem studies had been reported from $5 \%$ to $86 \%$ [1-11]. However, the prevalence of myocardial bridging among patients with conventional coronary angiography varied from $0.5 \%$ to $33 \%$ [12-27]. The discrepancy may be partly due to that the compression during systole is little and lack of provocation with nitroglycerin at the time of angiography. In a large cohort study of Chinese patients, myocardial bridging is up to $16.1 \%$ after intracoronary nitroglycerin [27]. It was reported that the incidence of myocardial bridging may be as high as $40 \%$ in patients with coronary angiography when positive inotropic medication but not nitroglycerin is used as prevocational agent[23]. Another reason may be partly due to that myocardial bridging does not always induce dynamic compression at conventional angiography. In that case, it is difficult to unmask the myocardial bridging at conventional angiography [28].

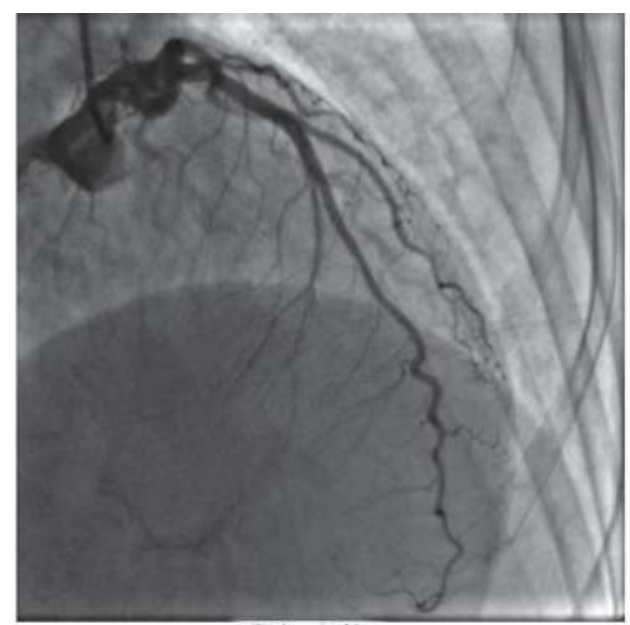

Diastolic

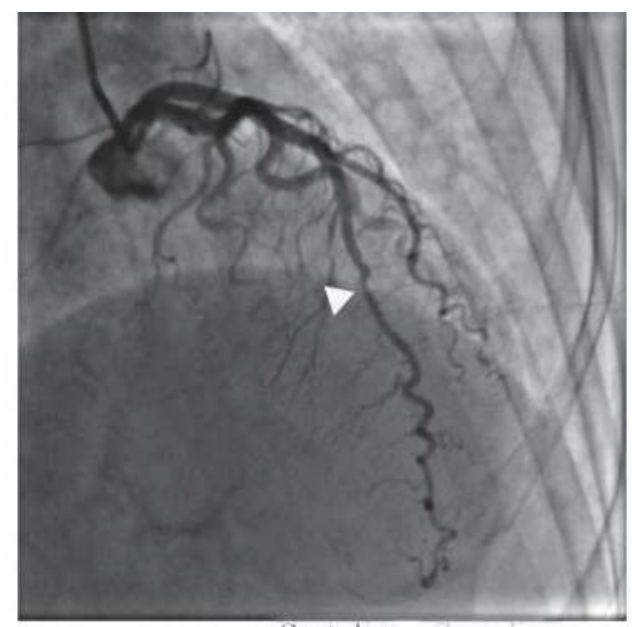

Systolic

Fig. 1. One case of myocardial bridging on conventional angiography. Compression of coronary artery during systolic occurs at the middle segment of left anterior descending artery (white arrow) and relaxation at diastolic phase.

It was reported that myocardial bridging is higher in patients with heart transplant recipients. In 33\% of 64 heart transplant patients, myocardial bridging is detected. The higher incidence might be related increased stiffness and hypertrophy of myocardium[20]. At the circumstance of myocardial hypertrophy, vigorous contraction facilities the detection of myocardial bridging. A higher prevalence of myocardial bridging had also been reported in patients with hypertrophy. Multiple sites of myocardial bridging may be occurred in patients with hypertrophic obstructive cardiomyopathy[29].

Most of myocardial bridging is occurred at the site of LAD. However, myocardial bridging of right coronary and left circumflex is reported not only at postmortem studies but also conventional angiographic studies[30]. The incidence of myocardial bridging at the site of LAD shows no difference at different age and sex[12]. 


\section{Classification of myocardial bridging}

At postmortem studies, Ferreira et al distinguished between two types of bridging: (1) superficial bridges (75\% of cases) crossing the artery perpendicularly or at an acute angle toward the apex, and (2) muscle bundles arising from the right ventricular apical trabeculae ( $25 \%$ of cases) that cross the LAD transversely, obliquely, or helically before terminating in the interventricular septum[8].

Superficial or deep myocardial bridges form in utero at the time of cardiac development. In most individuals they do not cause symptoms but particularly in those with deep myocardial bridges, the anatomical relation of the myocardial fibers can distort the artery that can be identified angiographically. The possibility of myocardial bridges should be borne in mind in individuals with ischemia but no evidence of coronary atherosclerosis.

Based on conventional angiography, myocardial bridging is classified as three groups according to the percentage of systolic compression of left anterior descending coronary artery. Systolic compression less than $50 \%$ was classified as group I. Systolic compression between $50 \%$ and $70 \%$ represented group II. Patients with systolic compression $\geq 70 \%$ represented group III. [12].

Schwarz proposed a new MB classification for symptomatic patients with MB. Three types of myocardial bridging were divided. Type A indicates patients with $\mathrm{MB}$ with no objective signs of ischemia. MB was detected occasionally. Type B indicates patients with MB with objective signs of ischemia. Type $C$ indicates patients with or without objective signs of ischemia and altered intracoronary hemodynamics (by QCA/CFR/intracoronary Doppler). The classification is of clinical importance since 5-year follow-up showed that type B responded well to beta-blockers or calcium channel antagonists [31].

Based on computed topography angiography(CTA), MB can be classified as three types. Type I is myocardial bridging with partial encasement as LAD being within the interventricular gorge and in direct contact with left ventricular myocardium. Type II is myocardial bridging with full encasement as LAD being surrounded by myocardium but

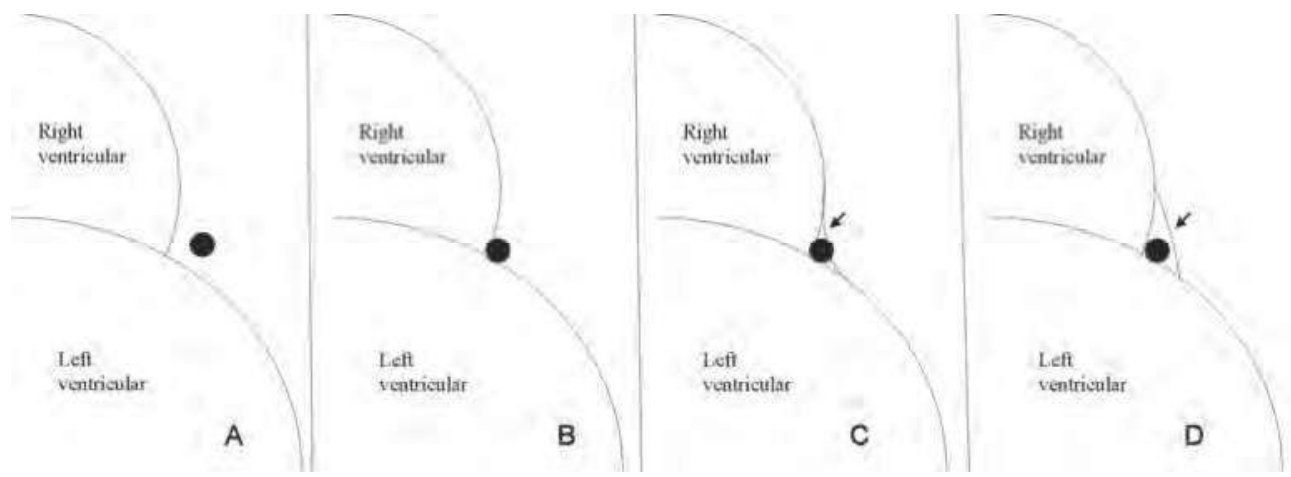

Fig. 2. Schematic illustration of classification of MB at MDCT. At normal condition, coronary runs through the ventricular septal without contacting with myocardium(A). When the artery is closely contacting with septal myocardium without myocardium overlying it, it is classified as partial encasement(B). If there is myocardium overlying the artery, it is called full encasement( $C$ and $D$, arrow indicates myocardium overlying coronary artery). The full encasement is further classified as overlying myocardium without measurable (less than $0.7 \mathrm{~mm}, \mathrm{C}$ ) and measurable type (D) [28]. 
without measurable overlying myocardium. Type III is myocardial bridging with full encasement as LAD being surrounded by myocardium but with measurable overlying myocardium $(>0.7 \mathrm{~mm})$ [28](Figure 2$)$.

\section{Modern view of MB}

Usually, dynamic compression of myocardial bridging is caused by myocardium overlying tunneled artery. During systolic phase, contraction of myocardium induces stenosis of coronary artery, while coronary artery turns to normal because of the relaxation of myocardium during diastolic phase. However, recent study by Kim et al raised some new features on MB. They demonstrated that systolic compression does not always occur in segments with overlying muscle. Dynamic compression affects only one third of patients with overlying myocardium. The length of dynamic compression was longer than that of tunneled segment. It suggested that coronary artery entrapped within the interventricular gorge is the mechanism of dynamic compression [28].

\section{Mechanisms for atherosclerosis and ischemia}

Myocardial bridging is usually considered as a benign condition since coronary flow is maximal during diastole but not systole. However, frame by frame analysis of myocardial bridging at intrvascular ultrasound (IVUS), which half moon phenomenon is seen as new characteristic at IVUS, showed delayed relaxation during early diastole [32]. At the same time, studies with intracoronary Doppler in patients with myocardial bridging showed that a peak of high flow velocity was detected in early diastole [33-34]. The reason for this hemodynamic disturbance may be related to the pressure gradient between the proximal and distal segment of myocardial bridging. The lower shear stress may contribute to atherosclerosis at proximal segment of myocardial bridging, whereas higher shear stress may protect it from atherosclerosis at the tunneled segment of myocardial bridging, which is of interest to study [35].

Also, those high pressure gradients ultimately increase local wall tension and subsequent endothelial dysfunction and atherosclerosis formation at the proximal segment. The extent of atherosclerosis is higher in the proximal segment of myocardial bridging than the tunneled segment is attributed to the higher expression of eNOS, ET-1 and ACE [36]. Recent study showed that properties of the MB enhance the development of atherosclerosis in the LAD proximal to the MB, resulting in MI[37]. Studies by MDCT showed that length and thickness of $\mathrm{MB}$ as well as $\mathrm{MB}$ location are associated with the formation of culprit lesions of LAD proximal to MB in MI. In myocardial infarction (MI) patients with culprit lesions in the LAD proximal to $M B, M B$ length, $M B$ thickness, and index of the length multiplied by thickness of $\mathrm{MB}$ were significantly greater than non-culprit group. The distance from the orifice of the left main trunk to MB entrance was anatomical significantly shorter [38]. It further supports the notion that anatomatical properties of $\mathrm{MB}$ are associated with atherosclerosis at proximal segment of MB.

It demonstrated that coronary atherosclerosis is more pronounced and extended up toward to the coronary ostium. It suggests that myocardial bridging enhances the predisposition to coronary atherosclerosis and myocardial infarction. This novel anatomic risk factor for coronary atherosclerosis and myocardial infarction changes previous opinion that myocardial bridging is considered as a benign condition. Future studies must demonstrate not only the presence of bridging but also the disease stage and the presence of signs of 
complicated lesions, which may be an even more pronounced hint of the anatomic risk factor for a acute coronary events.[39]

Ischemia induced by myocardial bridging is related to several reasons. In addition to systolic compression and delayed diastolic relaxation, vasospasm of coronary artery may be another mechanism. The considerable delay in blood flow and reduced distal coronary pressure are presumed to impair coronary vasodilator reserve, which may induce ischemia in patients with myocardial bridging. Another reason for coronary ischemia may be related to coronary spasm, of which is stimulated by endothelial dysfunction of coronary artery. Coronary angina even myocardial infarction may occur in this situation.

\section{Detection of myocardial bridging using non-invasive method}

\section{Multi-detector computed tomography (MDCT) Technique}

The heart is moving fast during computed tomography imaging. So it requires a higher temporal resolution and higher spatial resolution for visualization of coronary artery as well as myocardial bridging. Despite improvement of imaging acquisition of coronary artery, there is still some gap between coronary CT angiography and invasive coronary angiography. At normal condition, temporal resolution of MDCT((4-MDCT, 250 milliseconds; 16-MDCT, 183250 milliseconds; 64-MDCT, 165-210 milliseconds) is much more lower than that of invasive coronary angiography( $<10$ milliseconds). However, with dual source CT, the temporal resolution can be achieved less than 100 milliseconds, which eliminates the need for cardiac control before coronary CT angiography with beta-blockers. When beta-blockers is used before imaging acquisition, it may reduce the systole compression and decrease the detection rate of myocardial bridging. Furthermore, the use of dual source CT may manifest the milking effect, as shown in invasive coronary angiography. [40]

\section{Myocardial bridging on MDCT}

\section{6-MDCT}

Although conventional coronary angiography is considered as golden standard for detecting myocardial bridging, other techniques are also used at clinical, including intravascular ultrasound and Doppler. However, they are all invasive method with much trauma and not cost-effectiveness. With the advance of multi-detector row spiral computed tomography(MDCT) and multiplanar reconstruction, coronary artery disease is possible to be visualized accurately and non-invasively.

At the beginning, myocardial bridging is estimated about $22(3.5 \%)$ of the unselected 626 patients with 16-MDCT scanners, $15(2.4 \%)$ at the middle segment of LAD, $5(0.8 \%)$ at the distal segment of LAD and $2(0.3 \%)$ at proximal segment of LAD. The length and depth of myocardial bridging is between 6 and $22 \mathrm{~mm}$ (mean, 17mm) and between 1.2 and $3.3 \mathrm{~mm}$ (mean, $2.5 \mathrm{~mm}$ ). [41] In their study, they first examine axial resource and the multiplanar reconstructions for all patients. Myocardial bridging is diagnosed if coronary vessel coursing in the muscle or getting closer to the septum. By means of changing the window width and level, the muscle fibers overlying the coronary and the narrowing of the vessel at this area can be analyzed. Compared with detection of myocardial bridging with coronary angiography, MDCT does not require an experienced eye and deep style myocardial bridge. It is more easily to unveil the mask of bridging even a few muscles overlying the tunneled artery based on constructional 3D volume-rendering images. [41] 
In another study with 16-row MDCT of 148 patients with coronary heart disease, 23 patients $(15.8 \%)$ with myocardial bridging is detected over $1.0 \mathrm{~mm}$ in thickness: $21(87.5 \%)$ were located in LAD with a mean thickness and length of $1.8 \pm 0.7$ and $20.0 \pm 8.6 \mathrm{~mm}$. Moreover, although the tunneled segment beneath MB was always free of coronary wall lesions, $79.2 \%(19 / 24)$ of the segments proximal to MB demonstrated coronary wall lesions. Of special significance were three symptomatic MB patients without any atherosclerotic lesion throughout all the coronary arteries. [42]

\section{4-MDCT}

In a study, 277 patients studied with 64-slice MDCT for suspected or known coronary atherosclerosis were retrospectively reviewed for myocardial bridging. MB was presented in

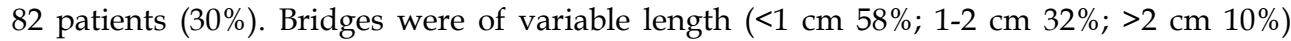
depth (superficial 69\%, intramyocardial 31\%) and frequently localized in the mid-distal segment of the left anterior descending artery (95\%). Coronary segments proximal to the bridge showed no atherosclerotic disease $(33 \%)$, positive remodeling $(27 \%),<50 \%$ stenosis $(20 \%)$ or $>50 \%$ stenosis $(20 \%)$. In this study, 12 non-calcified, 32 mixed and 17 calcified plaques were identified. The distal segments were significantly less affected $(p<0.0001)$. [43]

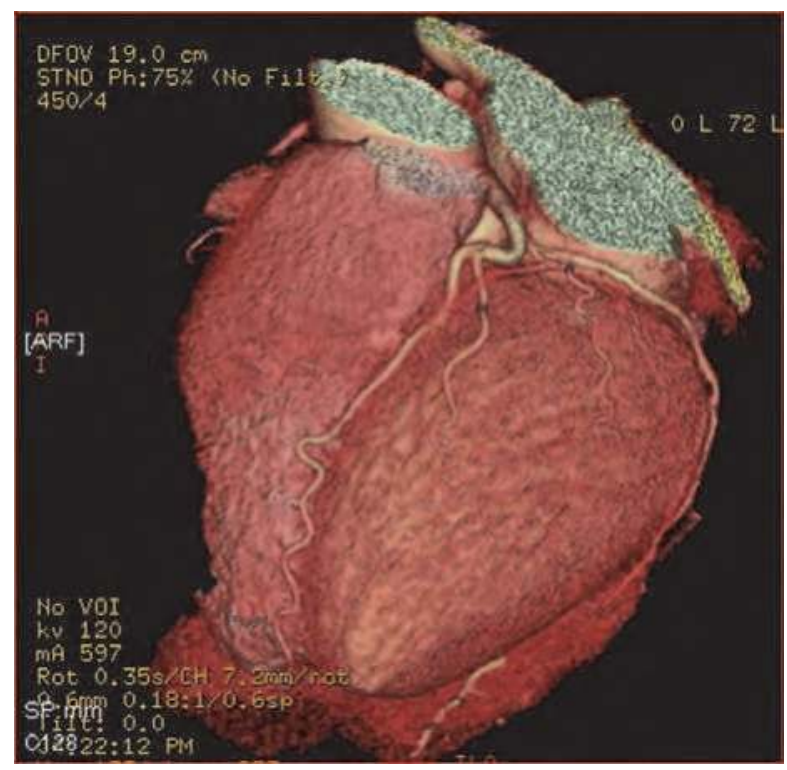

Fig. 3. MB at 64-MDCT. It clearly demonstrates that coronary artery coursing through myocardium at the middle segment of LAD.

\section{8-MDCT}

Lazoura et al evaluates the prevalence, length, depth, and location of myocardial bridging of the coronary arteries using 128-MDCT. 875 patients were enrolled in this study. 184 subjects $(21 \%)$ were found to a single myocardial bridge, including complete bridging in 161 patients $(18.4 \%)$ and incomplete bridging in 23 patients $(2.6 \%)$. Most of MB were at the middle segment of $\operatorname{LAD}(67.9 \%)$. The mean length and maximum myocardial thickness overlying 
the complete bridging were $20.9 \mathrm{~mm}$ (range 8-32mm) and $2.6 \mathrm{~mm}$ (range 1.2-5.3 $\mathrm{mm}$ ), respectively. The mean length of the incomplete bridging was $17 \mathrm{~mm}$ (range 9-2.3 $\mathrm{mm}$ ). [44]

\section{Dual source MDCT}

Dual source MDCT has fewer imaging time and better resolution for detecting myocardial bridging and is not influenced by heart rate. The results by Hwang et al showed that 536 patients of the 1,275 patients (42\%) were found with MB in this study. Superficial MB was observed in 368 of 557 (66\%) cases, and deep MB was seen in 189 of 557 (34\%) cases. Superficial MB showed 2 types: complete (128 of 368, 35\%) and incomplete ( 240 of 368, 65\%).The mean length of a tunneled segment for superficial MB was $16.4 \pm 8.6 \mathrm{~mm}$. The mean length and depth of a tunneled segment for deep $\mathrm{MB}$ were $27.6 \pm 12.8 \mathrm{~mm}$ and $3.0 \pm 1.4 \mathrm{~mm}$, respectively. The incidence of atherosclerotic plaques in a 2-cm-long segment proximal to $\mathrm{MB}$ was $16 \%$ [45]. Studies evaluate MB using MDCT are illustrated in table 1

\begin{tabular}{|c|c|c|c|c|}
\hline Author (Refer.) & Sample size & Frequency (\%) & MDCT & Comment \\
\hline Takamura et al 38 & 228 & 18.9 & 16 & AMI patients \\
\hline Ou et al 46 & 2530 & 5.4 & DSCT & All patients \\
\hline Kim et al 47 & 607 & 6.42 & 64 & All patients \\
\hline La Grutta et al 43 & 277 & 30 & 64 & $\begin{array}{l}\text { Suspected or known } \\
\text { coronary artery disease }\end{array}$ \\
\hline Lazoura et al ${ }^{44}$ & 875 & 21 & 128 & All patients \\
\hline Bayrak et al 48 & 990 & 22.5 & 64 & All patients \\
\hline Liu et al 49 & 3011 & 5.8 & 64 & Coronary heart disease \\
\hline De Rosa 50 & 235 & 48.7 & 16 & Atypical chest pain \\
\hline Jacobs 51 & 506 & 10.4 & 64 & All patients \\
\hline Atar 52 & 165 & 17 & 64 & All patients \\
\hline Zeina 53 & 300 & 26 & $16(226), 64(64)$ & All patients \\
\hline Yang 54 & 900 & 18.6 & 64 & $\begin{array}{l}\text { Suspected coronary artery } \\
\text { disease }\end{array}$ \\
\hline Kawawa ${ }^{55}$ & 148 & 15.8 & 16 & Coronary heart disease \\
\hline Hwang 45 & 1275 & 46 & DSCT & All patients \\
\hline Chen 56 & 114 & 50 & 64 & APH patients \\
\hline Koşar et al 57 & 700 & 37 & 64 & $\begin{array}{l}\text { Suspected or known } \\
\text { coronary artery disease }\end{array}$ \\
\hline Chen $^{58}$ & 276 & 8.7 & 16 & All patients \\
\hline Kim 28 & 300 & 58 & 64 & $\begin{array}{l}\text { Suspected or known } \\
\text { coronary artery disease }\end{array}$ \\
\hline Jodocy 59 & 221 & 23 & 64 & All patients \\
\hline Lubarsky ${ }^{60}$ & 245 & 44 & 64 & All patients \\
\hline Konen 61 & 118 & 30.5 & 64 & All patients \\
\hline
\end{tabular}

DSCT indicates dual source computed tomography; APH: apical hypertrophic cardiomyopathy Table 1. Illustration of MB at different MDCT studies 


\section{Comparison of coronary CT angiography and invasive coronary angiography for detection of myocardial bridging}

Several studies have explored the effect of MDCT and invasive coronary angiography for detection of myocardial bridging. Leschka et al studied 100 patients (38 women, 62 men; mean age, $63.8 \pm 11.6$ years) who underwent 64 -section MDCT and conventional coronary angiography. They found that the depiction rate of $\mathrm{MB}$ is greater with 64-section MDCT coronary angiography than with conventional coronary angiography. MB was detected with MDCT in $26(26 \%)$ of 100 patients and with conventional angiography in 12 patients (12\%). In 14 patients in whom MB was found at MDCT but not at conventional angiography, length, depth, and systolic compression were significantly lower than in patients in whom both modalities depicted the anomaly. The degree of systolic compression of $\mathrm{MB}$ significantly correlates with tunneled segment depth but not length [62].

In another study with 120 patients who underwent MDCT and coronary angiography, 30 patients were observed with MB. The within-MB diameters on MDCT-CTA and coronary angiography showed a significant correlation during systolic and diastolic phases. In case of $\mathrm{MB}$, segments with sufficient systolic compression (>50\%), length of MBs on MDCT and coronary angiography correlated significantly not only at systolic phase but also at diastolic phase [63].

Kim et al in a study with 300 patients who received 64 section MDCT showed that frequency of $\mathrm{MB}$ was $58 \%$ which partial encasement of 57 patients and full encasement of 117 paxents, while only 40 patients (13.3\%; partial encasement in 1 patient and full encasement in 39) demonstrated dynamic compression at conventional angiography. The length of the dynamic compression was considerably longer than the respective tunneled segment in all patients. Total length correlated with the dynamic compression, but depth did not. The higher prevalence of $\mathrm{MB}$ on MDCT is considered to the inclusion of partial and full encasement on CTA, the use of short-axis images obtained perpendicular to the long axis of the LAD for all analysis and measurement, the consistently high image quality of CTA with 64-section CT, observation of a single artery (LAD) with a specific purpose and the convenience of their system for reviewers[28].

\section{Comparison of myocardial bridging detection by MDCT with intravascular ultrasound}

The intravascular ultrasound has also been used to study MB. Instead of systolic compression, "half-moon" phenomenon has been demonstrated. It is specific for the existence of MB.[33,64]Invasive intravascular ultrasound (IVUS) is considered as the most accurate method for detecting MB under current situation. Data from our study showed that comparing with IVUS, the sensitivity of detection by MSCT was $93 \%$ and specificity was $100 \%$. Minimal and maximal diameters of MB derived from MSCT were significantly smaller than those from IVUS [65]. MSCT offers a reliable non-invasive method for MB in LAD and atherosclerosis diagnosis with diagnostic accuracy comparable with invasive IVUS.

From studies above, it can be concluded that prevalence of MB on MDCT is relatively high than we have thought to. The specificity and sensitivity on MDCT is higher than that on conventional angiography and is nearly equal to IVUS, which is thought to be golden 


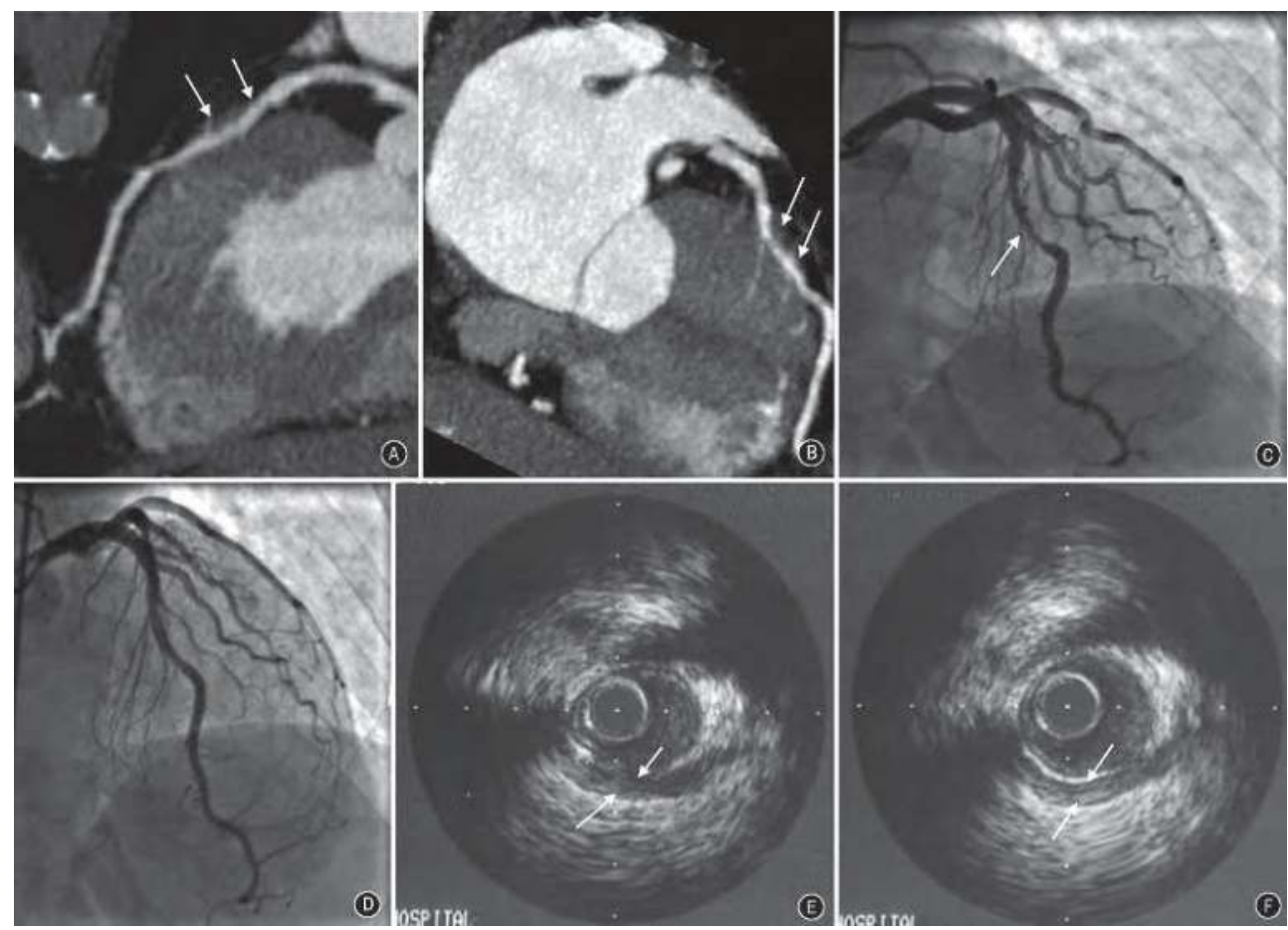

Fig. 4. MDCT,CAG and IVUS images in a patient with MB. MB at the middle segment of LAD is showed in MDCT image (A and B). Myocardium over tunneled artery is clearly demonstrated (arrows). The compression segment is much longer than the tunneled artery which suggests compression occurs not only at the segment with overlying myocardium. Coronary angiography clearly demonstrated the milking effect during systolic phase which is relaxed during diastolic phase (C and D). "Half moon" phenomenon is seen at IVUS both systole (E, arrows) and diastole (F, arrows)[65]. (Reprinted with permission of the author)

standard. The lower rate of $\mathrm{MB}$ on coronary angiography may be due to less compression during systole, shorter length of $\mathrm{MB}$, course of the tunnel segment. Not only $\mathrm{MB}$ can be assessed on MDCT, but also the atherosclerosis progress at the proximal segment of MB can be evaluated on MDCT during follow up. In the future, MDCT studies will need to evaluate the natural course of coronary atherosclerosis in those with and without myocardial bridging and to demonstrate whether the congenital variant is clearly a anatomic risk factor for myocardial infarction, possibly related to earlier onset and manifestation of coronary artery disease [39].

\section{Detection of MB with magnetic resonance imaging (MR)}

Substantial progress has been made since first study of visualizing coronary arteries in the late 1980s. [66-67]

The advantage of without contrast and radiation with MR makes it preferable for younger athletes and renal insufficient patients to identify possible coronary artery disease as well as 
MB. In addition, calcified lesions at MDCT images show positive diagnosis or cannot be clearly demonstrated for the artifact from calcification in many cases. Recent study by Liu et al showed that detection of calcified lesion of coronary artery by MR is better than that by MDCT [68].

At the beginning, a spoiled gradient-echo sequence at 3-dimensional coronary MR was used for detection of coronary artery disease [69]. Later, steady-state free precession (SSFP) imaging [70-71] was used to gain better image results. The major problems affecting coronary MR imaging are the long time scanning and artifacts induced by motion instability during long time scan. With the improvement in parallel processing, multichannel receiver coils and wide use of 3.0-T MR, it will be a promising method for assessing coronary artery disease as well as MB. However, artifact was much more common with the use of SSFP sequence when 3.0-T MR was applied to evaluate coronary artery. A spoiled gradient echo technique has gained much attention for better image quality and less artifacts.[72] Nowadays, the diagnostic accuracy of the coronary MRA technique to detect a patient with a $50 \%$ stenosis demonstrated a sensitivity of $88.7 \%$, a specificity of $82.1 \%$, a positive predictive value of $86.5 \%$, and a negative predictive value of $92 \%$.[73]

Recent study showed that coronary artery with diameter larger than $1.5 \mathrm{~mm}$ could be clearly assessed with $3.0 \mathrm{~T}$ MR, which in previous studies, only coronary artery with diameters larger than $2.0 \mathrm{~mm}$ be clearly evaluated.[74] In this circumstance, $\mathrm{MB}$ at the proximal and middle segment of LAD will be assessed very well.
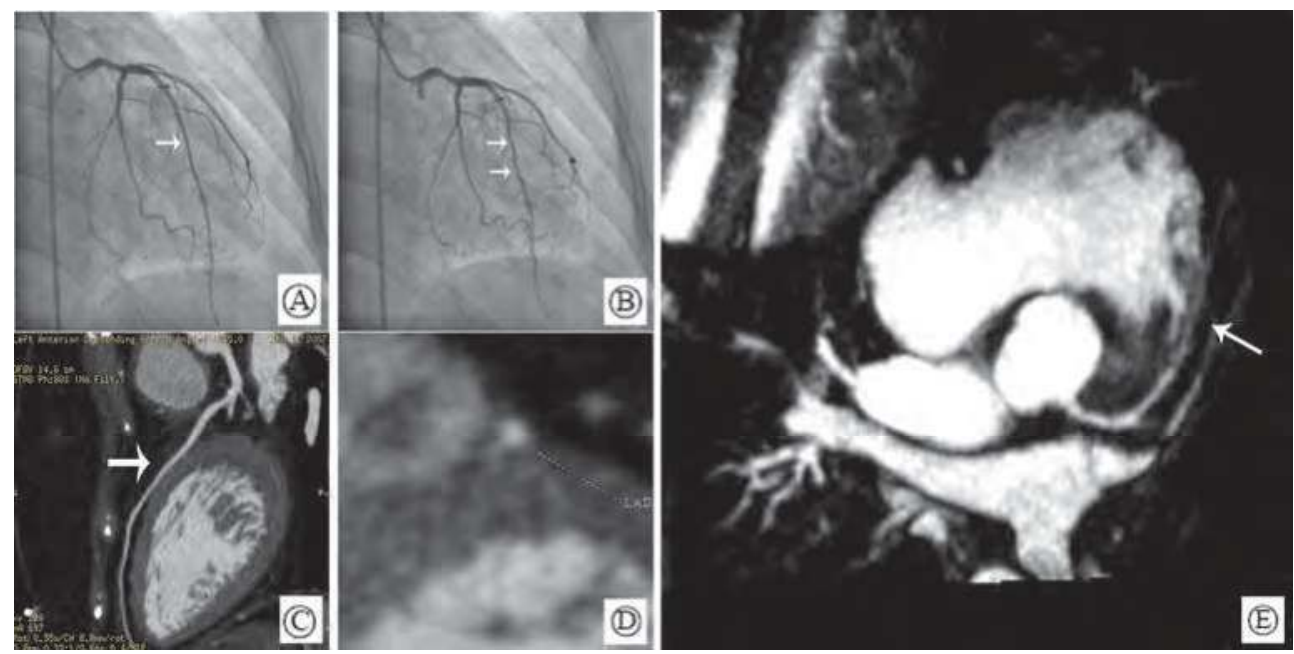

Fig. 5. CAG, MDCT and MR images in a patient with MB. MB at the middle segment of LAD is showed in coronary angiography image. A milking effect is seen during systolic phase(B, arrows) which is relaxed during diastole (A, arrow). Myocardium overlying tunneled artery is not demonstrated at MDCT (C, arrow and D). The compression segment at coronary angiography is longer that tunneled artery at MDCT. MB at the middle segment of LAD and compression of $\mathrm{MB}$ are showed at $\mathrm{MR}$ image (E, arrow). A soft plaque was demonstrated at proximal segment of LAD at MDCT image (C). 
However, until now, there is not a study to evaluate the prevalence of MB at coronary MR. It may be due to about one third of the patients can not complete the coronary MR imaging or the inability to evaluate all the coronary arteries in all patients [73]. In the further, more sensitive technique must be used in clinical for better image quality and shorter time scan. A pilot study should be prepared to assess the prevalence of $\mathrm{MB}$ and atherosclerosis progress induced by MB.

\section{References}

[1] Geiringer E. The mural coronary. Am Heart J. 1951;41:359-368.

[2] Edwards JC, Burnsides C, Swarm RL, et al. Arteriosclerosis in the intramural and extramural portions of coronary arteries in the human heart. Circulation. 1956;13:235-241.

[3] Pola'c ček P, Kralove H. Relation of myocardial bridges and loops on the coronary arteries to coronary occlusions. Am Heart J. 1961;61:44-52.

[4] Giampalmo A, Bronzini E, Bandini T. Sulla minor compromissione aterosclerotica delle arterie coronarie quando siano (per variante anatomica) in situazione intramiocardica. Giornale Ital Arterioscl. 1964;2:1-14.

[5] Lee SS, $\mathrm{Wu} \mathrm{TL}$. The role of the mural coronary artery in prevention of coronary atherosclerosis. Arch Pathol. 1972;93:32-35.

[6] Penther P, Blanc JJ, Boschat J, et al. L'artère interventriculaire antérieure intramurale: étude anatomique. Arch Mal Coeur. 1977;70:1075-1079.

[7] Risse M, Weiler G. Die koronare Muskelbrücke und ihre Beziehung zu lokaler Koronarsklerose, regionaler Myokardischämie und Koronarspasmus. Eine morphometrische Studie. Z Kardiol. 1985;74:700-705.

[8] Ferreira AG Jr, Trotter SE, König B, et al. Myocardial bridges: morphological and functional aspects. Br Heart J. 1991;66:364-367.

[9] Baptisda CAC, DiDio LJA. The relationship between the directions of myocardial bridges and the branches of the coronary arteries in the human heart. Surg Radiol Anat. 1992;14:137-140.

[10] Ortale JR, Gabriel EA, Lost C, et al. The anatomy of the coronary sinus and its tributaries. Surg Radiol Anat. 2001;23:15-21.

[11] Kosinski A, Grzybiak M. Myocardial bridges in the human heart: morphological aspects. Folia Morphologica. 2001;60:65-68.

[12] Noble J, Bourassa MG, Petitclerc R, et al. Myocardial bridging and milking effect of the left anterior descending coronary artery: normal variant or obstruction? Am J Cardiol. 1976;37:993-999.

[13] Binet JP, Guiraudon G, Langlois J, et al. Angine de poitrine et ponts musculaires sur l'artère interventriculaire anterieure: a propos trois cas opérés. Arch Mal Coeur. 1978;71:251-258.

[14] Ishimori T. Myocardial bridges: a new horizon in the evaluation of ischemic heart disease. Cath Cardiovasc Diagn. 1980;6:355-357.

[15] Greenspan M, Iskandrian AS, Catherwood E, et al. Myocardial bridging of the LAD: evaluation using exercise thallium-201 myocardial scintigraphy. Cathet Cardiovasc Diagn. 1980;6:173-180. 
[16] Rossi L, Dander B, Nidasio GP, et al. Myocardial bridges and ischemic heart disease. Eur Heart J. 1980;1:239-245.

[17] Voss H, Kupper W, Hanrath P, et al. Klinik, Laktatmetabolismus, Koronarvenenfluss und biphasisches 201-Thallium-Myokardscintigramm beiMyokardbrücken des Ramus Descendens Anterior: Verlaufsvariante oder Obstruktion? Z Kardiol. 1980;69:347-352.

[18] Kramer JR, Kitazume H, Proudfit WL, et al. Clinical significance of isolated coronary bridges: benign and frequent condition involving the left anterior descending artery. Am Heart J. 1982;103:283-288.

[19] Garcia JF, Villalon AM, Chavero EP. Significado clinico de las bandas musculares en las arterias coronaries. Arch Inst Cardiol Méx. 1983;53:413-420.

[20] Wymore P, Yedlicka JW, Garcia-Medina V, et al. The incidence of myocardial bridges in heart transplants. Cardiovasc Intervent Radiol. 1989;12:202-206.

[21] Somanath HS, Reddy KN, Gupta SK, et al. Myocardial bridge: an angiographic curiosity? Indian Heart J. 1989;41:296-300.

[22] Gallet B, Adams C, Saudemont JP, et al. Pont myocardique de l'artère interventriculaire anterieure et infarctus du myocarde. Le spasme coronarie a-t-il un rôle? Arch Mal Coeur. 1991;84:517-523.

[23] Diefenbach C, Erbel R, Treese N, et al. Häufigkeit von Myokardbrücken nachadrenerger Stimulation und Nachlastsenkung bei Patienten mit Angina Pectoris, aber unauffälligen Koronararterien. Z Kardiol. 1994;83:809-815.

[24] Juillière $\mathrm{Y}$, Berder V, Suty-Selton $\mathrm{C}$, et al. Isolated myocardial bridges with angiographic milking of left anterior descending coronary artery: a long-term follow-up study. Am Heart J. 1995;129:663-665.

[25] Harikrishnan S, Sunder KR, Tharakan J, et al. Clinical and angiographic profile and follow-up of myocardial bridges: a study of 21 cases. Indian Heart J. 1999;51:503507.

[26] Li JJ, Shang ZL, Yao M, Li J, Yang YJ, Chen JL, Qiao SB, Ma WH, Qin XW, Liu HB, Wu YJ, Yuan JQ, Chen J, You SJ, Dai J, Xu B, Xia R, Gao RL. Angiographic prevalence of myocardial bridging in a defined very large number of Chinese patients with chest pain. Chin Med J. 2008;121: 405-408.

[27] Qian J, Zhang F, Dong M, Ma J, Ge L, Liu X, Fan B, Wang Q, Cui S, Ge J. Prevalence and characteristics of myocardial bridging in coronary angiogram: data from consecutive 5525 patients. Chin Med J. 2009;122: 623-625.

[28] Kim PJ, Hur G, Kim SY, Namgung J, Hong SW, Kim YH, et al. Frequency of myocardial bridges and dynamic compression of epicardial coronary arteries: a comparison between computed tomography and invasive coronary angiography. Circulation 2009;119:1408-1416

[29] Wu W, Chen Z; Wang S, Huang T. Multiple Myocardial Bridging in Patients with hypertrophic cardiomyopathy: Report of Two Cases. Acta Cardiologica Sinica 2002; 18(4):197-200

[30] Polacek P, Kralove H. Relation of myocardial bridges and loops on the coronary arteries to coronary occlusions. Am Heart J 1961; 61:44-52.

[31] Schwarz ER, Gupta R, Haager PK, vom Dahl J, Klues HG, Minartz J, Uretsky BF. Myocardial bridging in absence of coronary artery disease: proposal of a new 
classification based on clinical-angiographic data and long-term followup.Cardiology. 2009;112(1):13-21

[32] Erbel R, Rupprecht HJ, Ge J, Gerber T, Görge G, Meyer J. Coronary artery shape and flow changes induced by myocardial bridging. Echocardiography. 1993;1:71-77.

[33] Ge J, Jeremias A, Rupp A, Abels M, Baumgart D, Liu F, Haude M, Görge G, von Birgelen C, Sack S, Erbel R. New signs characteristic of myocardial bridging demonstrated by intracoronary ultrasound and Doppler. Eur Heart J. 1999;20:17071716.

[34] Klues HG, Schwarz ER, vom Dahl J, Reffelmann T, Reul H, Potthast K, Schmitz C, Minartz J, Krebs W, Hanrath P. Disturbed intracoronary hemodynamics in myocardial bridging: early normalization by intracoronary stent placement. Circulation. 1997;96:2905-2913.

[35] Malek AM, Alper SL, Izumo S. Hemodynamic shear stress and its role in atherosclerosis. J Am Med Assoc. 1999;282:2035-2042.

[36] Masuda T, Ishikawa Y, Akasaka Y, Itoh K, Kiguchi H, Ishii T. The effect of myocardial bridging of the coronary artery on vasoactive agents and atherosclerosis localization. J Pathol 2001;193:408-414.

[37] Ishikawa Y, Akasada Y, Suzuki K, Fujiwara M, Ogawa T, Yamazaki K, Niino H, Tanaka M, Ogata K, Morinaga S, Ebihara Y, Kawahara Y, Sugiura H, Takimoto T, Komatsu A, Shingawa T, Taki K, Satoh H, Yamada K, Yangida-Iida M, Shimokawa R, Shimada K, Nishimura C, Ito K, Ishii T. Anatomic properties of myocardial bridge predisposing to myocardial infarction. Circulation. 2009;120:376 -383.

[38] Takamura K, Fujimoto S,Nanjo S, Nakanishi R, Hisatake S, Namiki A, Ishikawa Y, Ishii $\mathrm{T}$, Yamazaki J.Anatomical characteristics of myocardial bridge in patients with myocardial infarction by multi-detector computed tomography. Circ J 2011;75:642648

[39] Erbel R, Ge J, Möhlenkamp S. Myocardial Bridging: A Congenital Variant as an Anatomic Risk Factor for Myocardial Infarction? Circulation 2009;120;357-359

[40] Hazirolan T,Canyigit M,Karcaaltincaba1M, Dagoglu MG, Akata D,Aytemir K, Besim A.Myocardial Bridging on MDCT. AJR 2007; 188:1074-1080

[41] Kantarci M, Duran C, Durur I, Alper F, Onbas O, Gulbaran M, Okur A. Detection of myocardial bridging with ECG-gated MDCT and multi-planar reconstruction. Am J Roentgenol. 2006;186:S391-S394.

[42] KawawaY,IshikawaY,GomiT,NagamotoM,TeradaH,IshiiT,KohdaE. Detection of myocardial bridge and evaluation of its anatomical properties by coronary multislice spiral computed tomography. Eur J Radiol.2007;61:130-138.

[43] La Grutta L, Runza G, Lo Re G, Galia M, Alaimo V, Grassedonio E, Bartolotta TV, Malagò R, Tedeschi C, Cademartiri F, De Maria M, Cardinale AE, Lagalla R, Midiri M.Prevalence of myocardial bridging and correlation with coronary atherosclerosis studied with 64-slice CT coronary angiography.Radiol Med. 2009;114(7):1024-36

[44] Lazoura O, Kanavou T, Vassiou K, Gkiokas S, V.FezoulidisI. Myocardial bridging evaluated with 128-multi detector computed tomography coronary angiography. Surg Radiol Anat 2010; 32:45-50

[45] Hwang JH, Ko SM, Roh HG, Song MG, Shin JK, Chee HK, Kim JS. Myocardial bridging of the left anterior descending coronary artery: depiction rate and morphologic 
features by dual-source CT coronary angiography. Korean J Radiol. 2010;11(5):51421

[46] Ou SX, Li XR, Peng GM, Zhang L, Li SN. Imaging of congenital coronary artery anomalies by dual-source computed tomography angiography. Zhongguo Yi Xue Ke Xue Yuan Xue Bao. 2010;32(6):690-4.

[47] Kim SY, Lee YS, Lee JB, Ryu JK, Choi JY, Chang SG, Kim KS. Evaluation of myocardial bridge with multidetector computed tomography. Circ J. 2010;74(1):137-41.

[48] Bayrak F, Degertekin M, Eroglu E, Guneysu T, Sevinc D, Gemici G, Mutlu B, Aytaclar $\mathrm{S}$. Evaluation of myocardial bridges with 64 -slice computed tomography coronary angiography. Acta Cardiol. 2009;64(3):341-6.

[49] Liu H, Huang MP, Liang $\mathrm{CH}$, Zheng JH, Wu ZB. Detection and its clinical value of myocardial bridging with 64-slice spiral CT coronary angiography. Nan Fang Yi Ke Da Xue Xue Bao. 2009;29(2):236-8.

[50] De Rosa R, Sacco M, Tedeschi C, Pepe R, Capogrosso P, Montemarano E, Rotondo A, Runza G, Midiri M, Cademartiri F. Prevalence of coronary artery intramyocardial course in a large population of clinical patients detected by multislice computed tomography coronary angiography. Acta Radiol. 2008;49(8):895-901.

[51] Jacobs JE, Bod J, Kim DC, Hecht EM, Srichai MB. Myocardial bridging: evaluation using single- and dual-source multidetector cardiac computed tomographic angiography. J Comput Assist Tomogr. 2008;32(2):242-6.

[52] Atar E, Kornowski R, Fuchs S, Naftali N, Belenky A, Bachar GN.Prevalence of myocardial bridging detected with 64-slice multidetector coronary computed tomography angiography in asymptomatic adults.J Cardiovasc Comput Tomogr. 2007;1(2):78-83

[53] Zeina AR, Odeh M, Blinder J, Rosenschein U, Barmeir E.Myocardial bridge: evaluation on MDCT. AJR Am J Roentgenol. 2007;188(4):1069-73.

[54] Yang L, Zhao LF, Li Y, Wang XJ, Zhao XH, Zhao SH, Zhao H, Wu J, Liu X, Cai ZL. Multi-slice computed tomography of myocardial bridge and mural coronary artery and clinical significance thereof. Zhonghua Yi Xue Za Zhi. 2006;86(40):2858-62

[55] Kawawa Y, Ishikawa Y, Gomi T, Nagamoto M, Terada H, Ishii T, Kohda E. Detection of myocardial bridge and evaluation of its anatomical properties by coronary multislice spiral computed tomography. Eur J Radiol. 2007;61(1):130-8

[56] Chen CC, Chen MT, Lei MH, Hsu YC, Chung SL, Sung YJ.Assessing myocardial bridging and left ventricular configuration by 64-slice computed tomography in patients with apical hypertrophic cardiomyopathy presenting with chest pain.J Comput Assist Tomogr. $2010 ; 34(1): 70-4$.

[57] Koşar P, Ergun E, Oztürk C, Koşar U. Anatomic variations and anomalies of the coronary arteries: 64-slice CT angiographic appearance. Diagn Interv Radiol. 2009;15(4):275-83

[58] Chen YD, Wu MH, Sheu MH, Chang CY. Myocardial bridging in Taiwan: depiction by multidetector computed tomography coronary angiography. J Formos Med Assoc. 2009;108(6):469-74.

[59] Jodocy D, Aglan I, Friedrich G, Mallouhi A, Pachinger O, Jaschke W, Feuchtner GM. Left anterior descending coronary artery myocardial bridging by multislice 
computed tomography: correlation with clinical findings. Eur J Radiol. 2010;73(1):89-95.

[60] Lubarsky L, Gupta MP, Hecht HS.Evaluation of myocardial bridging of the left anterior descending coronary artery by 64-slice multidetector computed tomographic angiography. Am J Cardiol. 2007;100(7):1081-2

[61] Konen E, Goitein O, Sternik L, Eshet Y, Shemesh J, Di Segni E. The prevalence and anatomical patterns of intramuscular coronary arteries: a coronary computed tomography angiographic study. J Am Coll Cardiol. 2007;49(5):587-93.

[62] Leschka S, Koepfli P, Husmann L, Plass A, Vachenauer R, Gaemperli O, Schepis T, Genoni M, Marincek B, Eberli FR, Kaufmann PA, Alkadhi H. Myocardial bridging: depiction rate and morphology at CT coronary angiography: comparison with conventional coronary angiography. Radiology. 2008;246:754-762.

[63] Jeong YH, Kang MK, Park SR, Kang YR, Choi HC, Hwang SJ, Jeon KN, Kwak CH, Hwang JY. A head-to-head comparison between 64-slice multidetector computed tomographic and conventional coronary angiographies in measurement of myocardial bridge. Int J Cardiol 2010;143(3):243-8.

[64] Ge J, Erbel R, Rupprecht HJ, et al. Comparison of intravascular ultrasound and angiography in the assessment of myocardial bridging. Circulation. 1994;89:17251732.

[65] Wang MH, Sun AJ, Qian JY, Ling QZ, Zeng MS, Ge L, Wang KQ, Fan B, Yan W, Zhang F, Erbel R, Ge JB. Myocardial bridging detection by non-invasive multislice spiral computed tomography: comparison with intravascular ultrasound. Chin Med J. 2008;121:17-21.

[66] Lieberman JM, Botti RE, Nelson AD. Magnetic resonance imaging of the heart. Radiol Clin North Am 1984;22:847-58.

[67] Paulin S, von Schulthess GK, Fossel E, Krayenbuehl HP. MR imaging of the aortic root and proximal coronary arteries. AJR Am J Roentgenol 1987;148:665-70.

[68] Liu X, Zhao X, Huang J, et al. Comparison of 3D free-breathing coronary MR angiography and 64-MDCT angiography for detection of coronary stenosis in patients with high calcium scores. AJR Am J Roentgenol 2007;189:1326 -32.

[69] Kim WY, Danias PG, Stuber M, et al. Coronary magnetic resonanceangiography for the detection of coronary stenoses. N Engl J Med 2001;345:1863-9.

[70] Deshpande VS, Shea SM, Laub G, Simonetti OP, Finn JP, Li D. 3D magnetizationprepared true-FISP: a new technique for imaging coronary arteries. Magn Reson Med 2001;46:494 -502.

[71] McCarthy RM, Desphande VS, Beohar N, et al. Three-dimensional breathhold magnetization-prepared TrueFISP: a pilot study for magnetic resonance imaging of the coronary artery disease. Invest Radiol 2007;42:665-70.

[72] Liu X, Bi X, Huang J, Jerecic R, Carr J, Li D. Contrast-enhanced whole-heart coronary magnetic resonance angiography at $3.0 \mathrm{~T}$ : comparison with steady-state free precession technique at 1.5T. Invest Radiol 2008;43:663-8

[73] Sibley CT, Bluemke DA. Will 3.0-T make coronary magnetic resonance angiography competitive with computed tomography angiography? J Am Coll Cardiol. 2009;54(1):77-8. 
[74] Yang Q, Li K, Liu X, et al. Contrast-enhanced whole-heart coronary magnetic resonance angiography at 3.0-T: a comparative study with $\mathrm{X}$-ray angiography in a single center. J Am Coll Cardiol 2009; 54:69-76. 


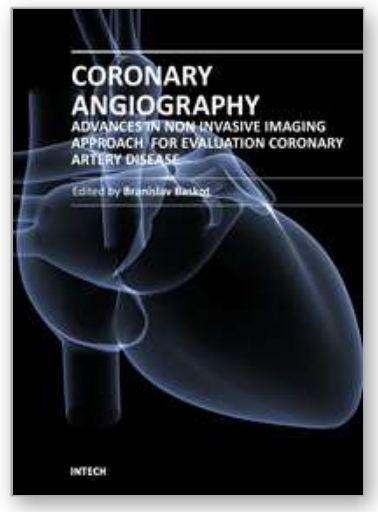

\author{
Coronary Angiography - Advances in Noninvasive Imaging \\ Approach for Evaluation of Coronary Artery Disease \\ Edited by Prof. Baskot Branislav
}

ISBN 978-953-307-675-1

Hard cover, 414 pages

Publisher InTech

Published online 15, September, 2011

Published in print edition September, 2011

In the intervening 10 years tremendous advances in the field of cardiac computed tomography have occurred. We now can legitimately claim that computed tomography angiography (CTA) of the coronary arteries is available. In the evaluation of patients with suspected coronary artery disease (CAD), many guidelines today consider CTA an alternative to stress testing. The use of CTA in primary prevention patients is more controversial in considering diagnostic test interpretation in populations with a low prevalence to disease. However the nuclear technique most frequently used by cardiologists is myocardial perfusion imaging (MPI). The combination of a nuclear camera with CTA allows for the attainment of coronary anatomic, cardiac function and MPI from one piece of equipment. PET/SPECT cameras can now assess perfusion, function, and metabolism. Assessing cardiac viability is now fairly routine with these enhancements to cardiac imaging. This issue is full of important information that every cardiologist needs to now.

\title{
How to reference
}

In order to correctly reference this scholarly work, feel free to copy and paste the following:

Junbo Ge and Jianying Ma (2011). Detection Myocardial Bridging Using Non-Invasive Technique, Coronary Angiography - Advances in Noninvasive Imaging Approach for Evaluation of Coronary Artery Disease, Prof. Baskot Branislav (Ed.), ISBN: 978-953-307-675-1, InTech, Available from:

http://www.intechopen.com/books/coronary-angiography-advances-in-noninvasive-imaging-approach-forevaluation-of-coronary-artery-disease/detection-myocardial-bridging-using-non-invasive-technique

\section{INTECH}

open science | open minds

\section{InTech Europe}

University Campus STeP Ri

Slavka Krautzeka 83/A

51000 Rijeka, Croatia

Phone: +385 (51) 770447

Fax: +385 (51) 686166

www.intechopen.com

\section{InTech China}

Unit 405, Office Block, Hotel Equatorial Shanghai

No.65, Yan An Road (West), Shanghai, 200040, China

中国上海市延安西路65号上海国际贵都大饭店办公楼 405 单元

Phone: +86-21-62489820

Fax: $+86-21-62489821$ 
(C) 2011 The Author(s). Licensee IntechOpen. This chapter is distributed under the terms of the Creative Commons Attribution-NonCommercialShareAlike-3.0 License, which permits use, distribution and reproduction for non-commercial purposes, provided the original is properly cited and derivative works building on this content are distributed under the same license. 